\title{
Capital e organização no capitalismo tecnoburocrático
}

Luiz Carlos Bresser-Pereira

O capitalismo e a modernidade nasceram da revolução capitalista que, com o Iluminismo e a Revolução Industrial, mudou a visão do homem sobre si mesmo, ao transformar o súdito em cidadão portador de direitos, e sobre a história, ao concebê-la como progresso. Nessa modernidade existe uma ampla camada média que não pertence nem à classe capitalista nem à trabalhadora, mas constitui uma terceira classe social: a classe tecnoburocrática ou profissional. Já não existe, portanto, o capitalismo clássico, que Marx analisou, e tampouco vingou o socialismo que ele previu. Materializou-se o estatismo nas sociedades que tentaram realizar a revolução socialista, enquanto o capitalismo se tornava tecnoburocrático. As revoluçóes socialistas resultaram em uma formação social estatal que não logrou constituir um modo de produção porque, ainda que distribuísse a renda de forma menos desigual, revelou ser uma forma de organização econômica e política incapaz de produzir a mesma riqueza que o capitalismo. Mas o resultado desse fracasso terá sido mesmo o surgimento de um capitalismo tecnoburocrático, ou seria mais razoável pensar em um capitalismo neoliberal?

Do ponto de vista das classes sociais e do fator estratégico de produção, o capitalismo contemporâneo pode ser definido como o capitalismo tecnoburocrático; do ponto de vista da coordenação econômica, como o capitalismo desenvolvimentista; do ponto de vista político, como o capitalismo democrático e social; do ponto de vista das relações entre as empresas no âmbito 
internacional, como capitalismo global. Rejeito, portanto, a ideia da existência de um capitalismo radicalmente liberal ou neoliberal coordenado quase exclusivamente pelo mercado, não obstante o mundo tenha sido dominado pela ideologia neoliberal entre 1979 e 2008 - entre a subida de Margaret Thatcher ao poder no Reino Unido e a crise financeira global de 2008. Ainda que possamos ver a relação entre o neoliberalismo e a globalização, uma vez que esta depende de que o mercado internacional esteja razoavelmente aberto, ela existiria mesmo com uma abertura menor. Além da relativa abertura dos mercados, o que a caracteriza é um fato novo de ordem tecnológica: a redução dos custos dos transportes e das comunicações internacionais. Logo, enquanto a globalização é o resultado de um fato novo de caráter tecnológico, o neoliberalismo é uma ideologia, que por sua vez não logrou mudar substancialmente a forma como o capitalismo é coordenado: não reduziu o tamanho do Estado nem aumentou a eficiência do sistema econômico; apenas favoreceu os mais ricos e causou um forte aumento da desigualdade econômica.

Neste trabalho, meu objeto é discutir o capitalismo tecnoburocrático, dos tecnoburocratas ou dos profissionais, que pode ser também chamado capitalismo organizado - porque é caracterizado pelas organizações públicas e privadas - ou, então, capitalismo do conhecimento - porque o fator estratégico que os profissionais dominam é o conhecimento. A grande discussão sobre o capitalismo pensado nesses termos ocorreu nos anos de 1970, o que não significa que seja hoje um problema ultrapassado. Apesar do ataque que sofreu durante trinta anos, esse sistema continua a ser caracterizado pela existência de duas classes dirigentes (a capitalista e a tecnoburocrática) que compartilham poder e privilégio. O neoliberalismo não foi apenas um ataque aos trabalhadores; foi também uma tentativa dos capitalistas rentistas associados aos financistas de recuperar o poder relativamente exclusivo que detinham sobre o Estado e sobre as grandes empresas burocratizadas. Contudo, esse ataque fracassou, e os tecnoburocratas são hoje tanto ou mais poderosos do que eram quarenta anos atrás. É verdade que hoje se discute menos intensamente a questão do capitalismo organizado e da nova classe social associada a ele, porque a resistência de uma parte dos marxistas em admitir uma terceira classe social perdeu força na medida em que o número de tecnoburocratas não parou de aumentar desde então. Outra explicação do lado neoliberal é a tese de que as classes sociais teriam perdido poder explicativo no capitalismo moderno. De fato, uma divisão dicotômica das classes e a previsão de que a classe trabalhadora seria revolucionária não se confirmaram. A luta de classes não teve, portanto, a intensidade esperada. 
Mas ela continuou muito presente como força dinâmica da sociedade. Por exemplo, como podemos pensar na aceitação pelos liberais do sufrágio universal sem considerarmos essa luta? Ao mesmo tempo, tornaram-se cada vez mais claras as coalizões de classe, isto é, a divisão da sociedade entre uma coalizão desenvolvimentista - formada principalmente pelos empresários industriais, os tecnoburocratas públicos e os trabalhadores - e uma coalizão liberal - formada por capitalistas rentistas e os financistas que administram a riqueza dos primeiros -, não obstante a fluidez e a complexidade das relações internacionais sociais nas grandes sociedades modernas.

O capitalismo tecnoburocrático é uma formação social mista, porque contém elementos de dois tipos "puros" de sociedades - do capitalismo e do estatismo. Enquanto a relação de produção fundadora do primeiro sistema é o capital - a propriedade privada dos meios de produção -, a do segundo é a organização: a propriedade coletiva da organização pela classe tecnoburocrática. Estou interessado em saber como essas duas relaçóes de produção ou essas duas "lógicas" que definem o capitalismo contemporâneo vêm se configurando e mudando, na medida em que o desenvolvimento econômico aumenta permanentemente o excedente econômico, promove a divisão do trabalho e torna a sociedade moderna cada vez mais complexa. Meu pressuposto sobre a política é de que embora as duas classes dirigentes dividam entre si poder e privilégio, elas são permanentemente pressionadas pelas classes populares que, no fim do século XIX, depois de uma intensa luta, conquistaram o sufrágio universal e, assim, tornaram possível se falar em democracia nos países mais desenvolvidos (cf. Przeworski, 1985, cap. 1). Meu pressuposto sobre a economia é de que cabe ao Estado o papel de principal instituição de coordenação econômica, que, naturalmente, é completada pelo mercado. Há, para isso, pelo menos três razões: primeiro, no plano microeconômico, o mercado não logra coordenar de maneira minimamente satisfatória o setor não competitivo da economia; segundo, no plano macroeconômico, o mercado é incapaz de coordenar a economia como um todo evitando graves crises financeiras; e, terceiro, no plano da distribuição, o mercado deixado sozinho produz desigualdades inaceitáveis em sociedades democráticas.

\section{Definições}

Os dois fatos históricos que, associados, fizeram o capitalismo se tornar tecnoburocrático foram a Segunda Revolução Industrial, no fim do século XIX - uma revolução tecnológica baseada na descoberta da eletricidade, no 
1. Peter Drucker (1968, pp. 247 e 326) falava de uma "economia do conhecimento" e de uma "sociedade do conhecimento", apontando que "os setores industriais baseados no conhecimento" e não na produção de bens e serviços, se em 1955 representavam um quarto do produto interno bruto dos Estados Unidos, dez anos mais tarde representavam um terço. Já naquela época, Drucker mencionava o "trabalhador do conhecimento" e assinalava "a emergência do conhecimento como um elemento central para nossa sociedade". O primeiro capítulo de seu livro de 1993 , Post-capitalist society, tem como título "Do capitalismo para a sociedade do conhecimento". motor a explosão e na linha de montagem -, e a revolução organizacional - o momento em que a unidade básica de produção deixou de ser a empresa familiar para ser a grande empresa burocrática ou, simplesmente, a organização empresarial, que é o sistema social administrado segundo o critério da racionalidade instrumental no qual o lucro é o objetivo e a administração eficiente, o meio para alcançá-lo. As duas transformações, iniciadas nos Estados Unidos, já indicavam o caráter hegemônico que esse país assumiria no século xx.

Em vez de capitalismo tecnoburocrático, eu poderia chamá-lo "capitalismo do conhecimento" se quisesse dar ainda mais ênfase ao papel do progresso técnico no capitalismo atual e se meu critério não fossem as classes dirigentes, mas o fator estratégico de produção que, na sociedade contemporânea, é o conhecimento. Essa denominação nasceu da identificação do conhecimento, por John Kenneth Galbraith (1968), como o novo fator estratégico de produção e da subsequente proposta de Peter Drucker (1968) de chamar a sociedade capitalista contemporânea de "sociedade do conhecimento" ". Na verdade, o conhecimento tornou-se o fator estratégico de produção e deu poder a seus detentores - os profissionais ou tecnoburocratas - também na virada para o século xx, quando a ciência passa a ser relevante para o desenvolvimento tecnológico. Mais tarde, a revolução da tecnologia da informação e da comunicação produziu um aumento extraordinário da quantidade de informação disponível, mas isso nem de longe significou um correspondente aumento do conhecimento. Daí resultaram imensas empresas que não produzem bens, mas serviços de informação, como é o caso da Microsoft ou da Google. Entretanto, como essas novas empresas não promoveram mudança nas relações de produção, não deram origem a uma nova classe. Já a revolução organizacional mudou a natureza do capitalismo: tornou-o misto, tecnoburocrático-capitalista. Poderia, por fim, chamá-lo também de capitalismo "organizado", nos termos discutidos por Claus Offe (1985) e por Lash e Urry (1987), porque desde a revolução organizacional as organizações são a unidade básica de produção.

Denomino a classe social que compete com a classe capitalista no comando das sociedades contemporâneas classe média profissional ou classe tecnoburocrática. Outras denominações existentes na literatura sociológica são classe burocrática, nova classe média e classe média assalariada. Todas são aceitáveis, mas as duas expressões sinônimas que utilizo me parecem mais adequadas; a primeira porque indica um tipo geral de especialista ou de administrador que usa seu conhecimento para dirigir e assessorar as organizações 
burocráticas; a segunda porque sugere a combinação do burocrata clássico com o técnico ou especialista moderno. A classe profissional é sempre uma classe média. Ao contrário do que acontece com o capitalista médio, que ao enriquecer ascende socialmente dentro da mesma classe, o profissional que se torna rico - algo cada vez mais frequente - passa a possuir capital e a fazer parte da alta burguesia. Ao se tornar rico e continuar ativo, esse profissional passa a participar das duas classes. É comum falarmos ou lermos sobre a grande "classe média" que caracteriza as sociedades modernas. De fato, ela é cada vez maior, mas devemos ter em mente que ali estão duas classes sociais: a pequena e média burguesia e a classe média profissional ${ }^{2}$.

Tecnoburocracia é o nome da classe profissional, mas pode ser usado também para identificar um sistema de dominação nos termos de Max Weber ([1922]* 1978) - um sistema dotado de legitimidade, na medida em que é exercido de forma racional-legal e que suas origens são ou pretendam ser técnicas ou profissionais. Desse ponto de vista, a tecnoburocracia conflita com a democracia. Não uso a palavra "tecnocracia", embora possamos considerá-la sinônima de "tecnoburocracia" - esta expressa melhor o sistema que pretendemos definir, porque além dos especialistas ou técnicos engloba os administradores ou gerentes e também os profissionais liberais e os professores. De mero estamento burocrático a serviço dos monarcas, no século $\mathrm{xx}$ esse estamento assumiu o caráter de uma classe social conforme o enorme aumento do número de seus membros implicou uma mudança qualitativa.

O conceito de profissional ou de tecnoburocrata que uso é amplo. Profissionais são os indivíduos que procuram racionalizar os métodos de produção; que têm um conhecimento sistematizado e aprofundado a respeito de uma técnica qualquer e utilizam esse conhecimento de forma profissional. Esse conhecimento pode ter sido obtido exclusivamente através da experiência, mas, em princípio, terá por base treinamento formal de nível universitário. $\mathrm{O}$ profissional é assim um administrador, um consultor ou um especialista que trabalha para organizações de forma direta ou terceirizada. Os professores, os cientistas, os animadores culturais e, mais amplamente, os intelectuais são também parte dessa classe, desde que seus rendimentos principais se originem de seu próprio trabalho e não de propriedades ou ativos que lhe propiciem rendas. Os profissionais liberais também fazem parte dessa terceira classe mesmo que prestem serviços diretamente às famílias. Entre os profissionais, estão os que dirigem outros homens (os administradores e os oficiais militares), aqueles capazes de desenvolver e manipular máquinas e matérias-primas de forma mais eficiente (os engenheiros e os técnicos de
2. Ou três classes, se, como Marx, distinguirmos a pequena burguesia da classe capitalista.

* A data entre colchetes refere-se à edição original da obra. Ela é indicada na primeira vez que a obra é citada. Nas demais, indica-se somente a edição utilizada pelo autor (N. E.) 
nível médio) e os que trabalham com ideias (intelectuais e cientistas). $\mathrm{O}$ conceito de profissional não é valorativo, mas, ao contrário do que ocorre com o burocrata, ele tem uma imagem positiva no mundo moderno; uma imagem que foi desafiada pelo neoliberalismo, mas sem êxito, afinal. Com frequência, o profissional é associado à razão, à lógica, à neutralidade ideológica e à eficiência. Nessa perspectiva, colocá-los no mesmo plano de um burocrata pode ser surpreendente. Da mesma forma, incluir entre eles os incompetentes e os carreiristas poderá também parecer estranho. Entretanto, uma vez que estou tentando analisar um ator social determinado - o profissional - e não um ser idealizado em nossas fantasias e aspirações, admitir a existência de profissionais incompetentes e carreiristas não tem nada de estranho. O que define o profissional é o papel que ele ocupa nas organizações burocráticas.

\section{Visões alternativas}

A Revolução Industrial tornou o capital a relação de produção dominante no capitalismo clássico; a Segunda Revolução Industrial e a revolução organizacional, associadas, promoveram a mudança do fator estratégico de produção do capital para o conhecimento técnico e administrativo e fizeram da emergência da classe profissional um fenômeno histórico definitivo. Diante desse fato, alguns sociólogos liberais, como Joseph Schumpeter, ao verem a nova classe surgir e o tamanho do aparelho do Estado aumentar, temeram pelo capitalismo. Outros, como Adolphe Berle, Daniel Bell e Ralph Dahrendorf, viram no surgimento dos profissionais ou dos gerentes uma profunda reorganização do sistema, que tornava a sociedade mais racional e livre dos conflitos de classe. Um terceiro grupo, formado por intelectuais como Wright Mills e John K. Galbraith, percebeu ainda que o capitalismo

3. Nessa questăo, o estatismo soviético e, depois, o chinês não tiveram sequer originalidade, porque a revolução industrial japonesa entre 1868 e 1908 foi inteiramente realizada pelo Estado. Mas, como a política japonesa de desenvolvimento era copiar não apenas a tecnologia mas também as instituiçōes ocidentais, entre 1908 e 1910 o governo promoveu a privatização de todo o setor competitivo da economia. mudara e que uma nova classe surgira, o que não significava que a sociedade deixaria de ser uma sociedade de classes. Por fim, um quarto grupo, do qual fizeram parte Bruno Rizzi, Cornelius Castoriadis, Claude Lefort e George Orwell, autor de $A$ revolução dos bichos, concentrou sua atenção na União Soviética e mostrou que a revolução socialista levara o país a uma sociedade tecnoburocrática e a um sistema político autoritário dominado por uma "nomenclatura" tecnoburocrática que ameaçava ser o modelo para todo o mundo. Mas, como sabemos, o capitalismo não foi superado pelo estatismo, que, afinal, foi apenas uma forma de revolução industrial atrasada na qual o Estado teve papel absoluto em vez de predominante ${ }^{3}$. Enquanto isso, no 
capitalismo avançado, ocorria uma revolução organizacional que deu origem a uma formação social mista, tecnoburocrático-capitalista.

Essas questões foram objeto de um grande debate nos anos de 1970, do qual participei. Marxistas que se pretendiam ortodoxos recusavam a ideia de uma nova classe não prevista por Marx, fosse porque, em relação aos países comunistas, não aceitassem que estivessem se transformando em estatismo burocrático, fosse porque, em relação aos países capitalistas avançados, não admitissem que o capitalismo deixara de ser uma sociedade de classes. Não tinham razão sobre o primeiro ponto, mas estavam corretos em relação ao segundo. A classe capitalista, agora associada à classe tecnoburocrática, continuou rica e poderosa. A separação entre a propriedade e o controle das empresas sem dúvida ocorreu nos Estados Unidos, mas raramente implicou a perda completa de poder dos acionistas. Conforme Maurice Zeitlin (1989, pp. 7-9), “gestão burocrática não significa controle burocrático; é preciso considerar os centros de controle no alto do sistema ou fora da burocracia propriamente dita”. É por essa razão que vejo o capitalismo tecnoburocrático como um sistema no qual capitalistas e profissionais partilham poder e privilégio e, ao mesmo tempo, lutam entre si para obter uma maior parcela desse poder e desse privilégio para seu grupo. São duas classes distintas e não, como sugere Zeitlin, "membros da mesma classe social". Para que essa afirmação fizesse sentido seria necessário ignorar as raízes históricas dessas duas classes sociais.

Hoje, essa discussão está terminada. É impossível ignorar ou rejeitar a emergência da classe profissional. Continua em aberto, entretanto, a questão do seu papel político. Sabemos que ela tem uma ideologia, mas daí não é possível deduzir um comportamento político coerente. Se no passado isso parecia possível, hoje deixou de ser, porque a classe tecnoburocrática se tornou grande e diversificada. Seus interesses estão relacionados ora com o Estado e o desenvolvimento econômico, ora com as empresas e seu crescimento. Ora seus líderes fazem uma coalizão política com os capitalistas ativos ou empresários e com os trabalhadores - e temos o fordismo, ou seja, uma coalizão de classes desenvolvimentista, como aconteceu em boa parte do século $\mathrm{xx}$-, ora se associam a rentistas e ao capital financeiro, como ocorreu nos anos neoliberais do capitalismo (1979-2008). Neste caso, estavam aceitando uma diminuição do poder, porque a hegemonia neoliberal que ocorreu nesse período foi dirigida não apenas contra os trabalhadores, ao procurarem reduzir seus direitos trabalhistas para tornar as empresas mais competitivas, mas também, senão principalmente, contra a tecnoburocra- 
cia, pois era ela que realmente competia com os capitalistas rentistas. Ao se associarem aos rentistas e financistas, estavam minando seu próprio poder, porque a coalizão financeiro-rentista se voltou tanto contra as conquistas sociais dos trabalhadores como contra o poder dos tecnoburocratas públicos e privados: no setor público, através da luta pelo Estado mínimo; no setor privado, através da luta dos acionistas contra o domínio dos altos executivos sobre as grandes empresas. Luta esta sempre moderada, contraditória, uma vez que a relação entre a burguesia e a tecnoburocracia é antes de acordo e concessões mútuas (compromises) que de conflito.

\section{A organização}

Entre outras coisas, o século xx foi marcado pelo capitalismo dos profissionais, em que uma nova relação de produção ou de propriedade - a organização - se definiu não em substituição, mas ao lado do capital. A distinção fundamental entre o modo de produção tecnoburocrático e o capitalista encontra-se na natureza das respectivas relações de produção, na forma que a propriedade assume em cada sistema. Segundo Marx, a propriedade é a forma jurídica de que se revestem as relaçôes de produção. Os modos de produção são categorias históricas em que a forma de propriedade, ou, mais precisamente, a relação de produção definida pela propriedade, constitui a característica essencial. À propriedade comunitária primitiva, à propriedade antiga, à propriedade asiática, à propriedade germânica, à propriedade feudal, à propriedade capitalista correspondem modos de produção respectivos. Isso está muito claro nos Grundrisse, em que Marx trata das formações pré-capitalistas (cf. Marx, [1858] 1971, vol. 1, pp. 434-444). Se a cada forma de propriedade corresponde uma relação de produção diferente, a cada uma corresponde também uma classe social distinta. A burguesia é a classe social dominante em uma sociedade capitalista porque é ela que detém a propriedade privada do capital; ela nasceu com o capitalismo e desapareceria com o advento de um modo de produção tecnoburocrático puro, quando surgiria a tecnoburocracia. Mas, em vez disso, o que vimos acontecer foi a transformação do capitalismo em uma forma mista de organização econômica e política do capitalismo - o capitalismo tecnoburocrático.

Ao modo de produção estatal corresponde a propriedade organizacional, ou simplesmente a organização, que pode ser definida como a apropriação coletiva pelos tecnoburocratas de cada organização burocrática. Quando esta- 
mos no estatismo, a propriedade dos meios de produção pertence ao Estado, e o aparelho ou organização do Estado é propriedade - está sob controle - de sua alta burocracia. Tal propriedade se materializa na ocupação de posições administrativas estratégicas nas organizações burocráticas privadas e nas do Estado. No caso do estatismo puro existe, a rigor, apenas uma organização burocrática - a organização do Estado das quais as empresas estatais são parte. A relação de produção tecnoburocrática é assim radicalmente diversa da capitalista, porque em uma a propriedade é coletiva e na outra, privada. Essa distinção torna-se mais clara se pensarmos em termos de propriedade organizacional. O tecnoburocrata é o profissional que dirige as organizações burocráticas, estas definidas em termos weberianos como sistemas sociais racionais, uma vez que são dotados de objetivos claros e administrados segundo o critério de eficiência. Não apenas o poder, mas também a própria existência do profissional depende da existência concomitante de uma organização burocrática. Na verdade, a organização burocrática antecede a classe profissional. Historicamente, as organizações burocráticas surgiram primeiro sob o controle patrimonial, em um quadro em que a burocracia pública era ainda um simples estamento, e depois sob o controle capitalista, em uma fase de transição. Só mais tarde o controle efetivo dessas organizações foi assumido pelos profissionais.

O importante, entretanto, é assinalar que, no sistema econômico tecnoburocrático, capital e organização estão associados no seio de um sistema ainda dominantemente capitalista. Além disso, uma vez que tanto no capitalismo tecnoburocrático como no desenvolvimentista o desenvolvimento econômico é o objetivo maior no plano econômico, as duas formas descrevem uma mesma realidade, ainda que uma enxergue o capitalismo do ponto de vista das classes sociais e do poder e a outra, do ponto de vista econômico. O lucro continua a ser o objetivo fundamental das empresas; no capitalismo tecnoburocrático, apenas se acrescenta a ele a expansão das empresas, embora sejam, em certos casos, objetivos conflitantes. O objetivo maior da sociedade continua a ser o desenvolvimento econômico (cf. Gellner, 1983), e a causa deste, a acumulação de capital com incorporação de progresso técnico. No sistema tecnoburocrático e desenvolvimentista, apenas se acentua a importância do planejamento dos setores não competitivos e de uma política econômica ativa para manter em equilíbrio os indicadores macroeconômicos - as taxas de câmbio, de lucro, de juros, de salários e de inflação. A especulação ainda é intrínseca aos mercados financeiros, mas o sistema financeiro é firmemente regulado. Trata-se de um capitalismo que é 
tecnoburocrático porque as grandes empresas são dirigidas por profissionais e as organizaçôes privadas visam ao lucro; que é desenvolvimentista porque o objetivo do Estado-nação é o desenvolvimento econômico e o meio para alcançá-lo é combinar a coordenação pelo mercado dos setores competitivos com o planejamento dos setores não competitivos, além de praticar uma ativa política macroeconômica.

No capitalismo tecnoburocrático, a organização está presente em toda parte, mas o capital também está. No capitalismo, a propriedade é privada e a classe dominante é a burguesia; no estatismo, a propriedade é coletiva e a classe dominante é constituída pelos profissionais. Há outros tipos de propriedades “coletivas”, expressão que utilizo aqui em oposição à propriedade privada: a propriedade asiática, em que um Estado burocrático-tradicional serve de mediador; a propriedade comunal da Europa pré-capitalista, coexistente com a apropriação privada feudal; a sociedade socialista, que, no entanto, prefiro não discutir por entender o socialismo como a ideologia da justiça social e como um projeto ou utopia, mais que como uma realidade possível no médio prazo. A existência da organização no capitalismo tecnoburocrático revela-se de muitas maneiras. Uma delas é o fato de que os altos executivos das grandes empresas comerciais e a alta burocracia pública são capazes de definir sua própria remuneração. Nas empresas comerciais, teoricamente, isso é atribuição do conselho de administração, mas muitas vezes esses conselhos são controlados por administradores e não por acionistas. No Estado, os funcionários públicos mais graduados, eleitos e não eleitos, muitas vezes têm um poder semelhante. $\mathrm{O}$ fato de os profissionais não deterem a propriedade legal, mas, em vez disso, a propriedade coletiva da organização, evidentemente reduz sua capacidade de definir seus proventos de modo pleno. Eles precisam constantemente justificar suas ações ou explicar sua remuneração em termos de mercado, enquanto o capitalista está livre para fazer uso de sua propriedade em seu próprio benefício e no de sua família.

Algo semelhante acontecia nos sistemas estatais. A nomenclatura - o conjunto dos altos profissionais que dominavam a União Soviética - enfrentava forte limitação em sua tentativa de se apropriar do excedente econômico. Como a propriedade dos profissionais não era herdada, a classe tecnoburocrática precisava adotar várias estratégias para transmitir suas posições de classe a seus descendentes, enquanto esse processo ocorre de modo relativamente automático no caso da classe capitalista (e mais ainda nas sociedades aristocráticas que imediatamente antecederam o capitalismo). Isso significa que a propriedade organizacional é menos definida e envolve 
menos poder do que a propriedade capitalista; que a organização é uma relação de produção que oferece menos estabilidade a seus proprietários do que o capital; e explica por que a mobilidade social tende a ser maior no capitalismo tecnoburocrático do que no capitalismo clássico ou liberal.

O ideal meritocrático - a esperança de que a desigualdade econômica fosse explicada apenas pelo mérito pessoal - era o sonho dos progressistas norte-americanos ${ }^{4}$. Na verdade, este é o sonho tecnoburocrático. A igualdade macroeconômica é substancialmente maior no estatismo do que no capitalismo; a desigualdade se expressa de maneira mais clara no plano político. Já o capitalismo tecnoburocrático implica um aumento da mobilidade social e, dependendo de como seja administrado - dependendo essencialmente da existência de um sistema tributário progressista como o dos países escandinavos -, pode apresentar ou não níveis razoáveis de igualdade econômica. A remuneração dentro da organização depende da posição ocupada pelo indivíduo - uma posição jamais segura, que deriva do monopólio sobre o conhecimento técnico, administrativo e comunicativo que o tecnoburocrata de fato tem ou supóe-se que tenha, de sua competência para administrar organizações burocráticas e de sua capacidade de criar redes sociais e transmitir valores e ideias através delas. Uma vez que a propriedade e as relações familiares cedem lugar ao mérito, em termos de justiça social há um avanço, longe de ser ideal, contudo, pelo fato de a remuneração dos altos executivos se tornar extremamente elevada, transformando-se em um fator de aumento das desigualdades (cf. Piketty, 2013). Mérito e poder organizacional tornam-se tão inter-relacionados que fica difícil saber qual critério prevalece.

\section{O novo conceito de capital}

Para Marx, o capital é a propriedade privada dos meios de produção da burguesia. Quando ele fala em capital variável e em capital constante, ou quando se refere a capital-dinheiro e a capital-mercadoria, pode-se imaginar que esteja dando ao capital um caráter material (Marx, [1867] 1968 , p. 885). Na verdade, o capital, como a própria mercadoria é para ele sempre um processo e uma relação de produção: "o capital não é uma coisa, mas uma relação social entre pessoas, efetivada através de coisas" (Idem, ibidem). Nos Grundrisse, Marx definiu a propriedade como uma relação social de produção real por meio da qual os homens tomam posse dos bens materiais, e não como um simples aspecto jurídico da relação de produção. "A propriedade não significa originariamente outra coisa senão
4. A mobilidade social com base no mérito "o sonho norte-americano" é identificada por Lloyd Warner (1953). 
o comportamento do homem com suas condições naturais de produção como sendo condições pertencentes a ele, suas, pressupostas juntamente com sua própria existência” (Marx, 1971, p. 452). Para Marx, portanto, ao contrário do que acontece no sistema jurídico moderno, propriedade não se distingue de posse. A propriedade é a própria relação de produção, é o controle que alguém tem dos bens. Em outras palavras, a propriedade é o elemento essencial e real das relações de produção, na medida em que define socialmente a apropriação dos meios de produção. Por isso, da mesma forma que Marx afirma que para cada modo de produção existe uma respectiva relação de produção, existe também uma correspondente forma de propriedade. A propriedade tem uma forma comunitária primitiva, ou asiática, ou eslava, ou germânica, ou antiga, ou feudal, ou capitalista, dependendo do caráter das relações de produção.

Não há nenhuma nominação espúria nessa forma de compreender a propriedade e relacioná-la com as respectivas relações de produção, mas simplesmente o reconhecimento da interdependência entre os conceitos de modo de produção, relação de produção e propriedade. Não por acaso, Marx utiliza sistematicamente o conceito de propriedade para identificar os diversos modos de produção. Praticamente repetindo sua definição de propriedade, afirma que "propriedade significa, portanto, originalmente - tanto em sua forma asiática, quanto eslava, antiga, germânica - o comportamento do sujeito que trabalha (produtor) (o que se reproduz), com as condições de sua produção ou reprodução como algo de seu" (Idem, p. 456). Não podem estar mais claros do que nesse texto, de um lado, o caráter de apropriação efetiva da propriedade - e não seu mero caráter jurídico - e, de outro, a importância crucial do conceito de propriedade para definir os modos de produção. A propriedade capitalista, nesses termos, é o próprio capital, entendido como relação de produção; é a apropriação privada, pela burguesia, dos meios de produção. A apropriação do capital sobre o trabalho coletivo, que de fato caracteriza as relações capitalistas de produção, só se configura a partir do momento em que o capitalista assume a propriedade privada dos meios de produção. Nesse instante, e concomitantemente, surgem o trabalho assalariado e o trabalhador coletivo na grande indústria, então definindo-se plenamente as relações de produção capitalistas. Propriedade privada capitalista, mercado e generalização da mercadoria, trabalho assalariado, mais-valia, trabalhador coletivo e grande indústria são aspectos interdependentes que, globalmente, integram as relações de produção capitalista, ou seja, configuram o capital. 
Com base no conceito de capital como propriedade dos meios de produção, a forma de medi-lo vem mudando com o tempo 5 . Para os economistas mercantilistas e os primeiros clássicos, ele era a propriedade do capital circulante: era essencialmente a capacidade de contratar trabalhadores, pagando-os antes que o resultado de seu trabalho pudesse ser vendido no mercado.

$\mathrm{Na}$ fase do capitalismo industrial e para os economistas desse período, a começar com Marx, o capital fixo havia se tornado o fator dominante, enquanto os trabalhadores podiam cada vez mais dispensar o pagamento prévio de seus salários. Em consequência, o capital passou a ser entendido como a propriedade de instalaçôes e equipamentos. Também passou a ser medido por seu patrimônio líquido, tal como identificado no balanço patrimonial. Algumas correçóes podiam ser feitas: o valor dos ativos intangíveis podia ser considerado, a avaliação contábil de certos bens de capital podia ser ajustada, mas, no fim, o valor da empresa era a soma dos ativos totais menos o passivo. Enquanto o capital físico era o fator estratégico de produção, medir o valor de uma empresa por seu patrimônio líquido contábil ou pelo retorno sobre o fluxo de caixa não fazia muita diferença. As duas medidas eram relativamente equivalentes, uma vez que se podia presumir que, em condições normais e dada a tendência à equalização das taxas de lucro $^{6}$, o resultado seria quase o mesmo, independentemente da escola de pensamento.

Nos anos de 1960 essa abordagem começou a ser abandonada, e surgiu uma terceira definição de capital, pela qual ele equivaleria ao valor descontado dos lucros futuros previstos (ou da geração de caixa) da empresa, com o desconto sendo realizado por uma taxa de retorno considerada "satisfatória” pelo mercado financeiro. Nenhum avaliador de empresas sério levará em conta o antigo sistema porque essa forma de medir o valor das empresas está consolidada. O que está por trás de tal mudança? Seria apenas um aperfeiçoamento dos métodos de análise, como presume a teoria econômica não histórica, ou existe algum fato histórico novo que tenha provocado essa alteração no método de medir o valor das empresas? $\mathrm{O}$ fato novo é a revolução organizacional; é o papel central que, a partir dela, as grandes empresas passam a ter no capitalismo tecnoburocrático. Hoje, o conhecimento incorporado nos principais executivos da empresa, no seu pessoal técnico e nos softwares é tão ou mais importante do que seus ativos imobilizados - o ativo maior a determinar seu lucro ou sua geração de caixa. Depois que o conhecimento administrativo se tornou estratégico, os analistas do mercado financeiro confirmam diariamente que o valor de
5. Estou ignorando a discussão entre os economistas keynesianos de Cambridge, Reino Unido, e de Cambridge, Estados Unidos. Foi uma discussão metafísica. Se não podemos medir capital, não sabemos qual é a taxa de lucro e, portanto, não temos teoria econômica.

6. Esta lei e a da oferta e da procura são as duas leis básicas de uma economia de mercado, mesmo quando o capitalismo é tecnoburocrático. 
uma empresa varia de modo dramático conforme a qualidade de sua gestão. Um novo diretor-presidente e um grupo de executivos mais competentes na direção de uma empresa poderão aumentar de forma significativa (ou diminuir, se forem incompetentes) seu fluxo de caixa e seus lucros em um período relativamente curto. Nesse caso, o antigo conceito de patrimônio líquido deixa de fazer sentido, enquanto a medida do valor do capital com base no fluxo de caixa se torna a única possibilidade racional, e a posição estratégica do profissional na empresa passa a ser decisiva.

$\mathrm{Na}$ medida em que o fluxo de caixa de uma empresa passa a depender da qualidade de sua alta direção - se esta for incompetente, o fluxo de caixa pode cair com rapidez, e vice-versa - compreendemos várias coisas. A primeira delas é por que a alta direção das grandes empresas vê seus rendimentos (salários, bônus, opções de compra de ações) e seu poder aumentarem diariamente. Compreendemos também a reação dos acionistas, que nos anos neoliberais lutaram para recuperar sua influência nas empresas, em geral com pouco sucesso. Só aumentando seu poder podem eles expelir as altas administraçōes incompetentes. Compreendemos ainda por que os grandes cursos de mestrado profissional nas grandes universidades são tão bem-sucedidos em atrair alunos. Eles são o caminho mais adequado para que os jovens se transformem em altos executivos. Por fim, compreendemos por que o abuso e a corrupção, em especial sob a forma de falsos demonstrativos contábeis, como aconteceu com a Enron, tornaram-se tão comuns no capitalismo dos profissionais contemporâneo, levando Galbraith (2004) a falar ironicamente sobre a "economia das fraudes inocentes". Como a remuneração dos altos executivos depende do desempenho das empresas, forjar bons resultados é uma tentação a que muitos são incapazes de resistir.

A remuneração elevada dos altos executivos é um dos fatores mais importantes a explicar o aumento da desigualdade que ocorre nos países desenvolvidos desde a segunda metade do século xx. As pesquisas realizadas por Thomas Piketty (2013) confirmaram amplamente essa afirmação. Embora sua preocupação maior seja mostrar que o valor do capital - especialmente do capital rentista - tende a aumentar, assim como a desigualdade, ele reconhece que a remuneração dos altos tecnoburocratas privados influencia o aumento das desigualdades, pois logo se transforma em capital rentista. Por fim, vale observar que, da mesma forma que o neoliberalismo não logrou, no plano político, diminuir o tamanho do Estado e a influência dos tecnoburocratas públicos, o ataque neoliberal dos acionistas aos executivos profissionais não obteve êxito: o poder dos tecnoburocratas privados continuou incólume. Eles 
cederam apenas ao concordar em distribuir mais dividendos aos acionistas do que gostariam de distribuir. Os acionistas geralmente demandam maior distribuição de dividendos, seja porque recebem caixa imediatamente, seja porque o valor das ações da empresa nas bolsas de valores aumenta quando dividendos são distribuídos.

Nesse processo de conquista crescente de poder e riqueza, os altos executivos profissionais, ao mesmo tempo que se mostravam necessários, buscaram sempre se aliar aos acionistas que substituíram na direção das empresas. O mecanismo básico utilizado com esse objetivo foi o de relacionar o valor das ações no mercado com sua remuneração pessoal sob a forma de bônus e opções de compra de açôes. Mas, afinal, foram eles os grandes beneficiados: nas quinhentas maiores empresas norte-americanas, a relação entre o pagamento recebido pelos CEOs (Chief Executive Officers) e o salário médio dos operários aumentou de trinta vezes, em 1970, para 570, em 2000 (Glyn, 2007, p. 58). Holmestron e Kaplan (2003, p. 13) observaram que "é difícil argumentar que essa gente necessitava incentivos tão grandes pagos pelos acionistas. Uma explicação óbvia é a de que eles puderam usar suas posições de poder para obter recompensas excessivas”.

Desde os anos de 1990, a remuneração dos CEOs nos Estados Unidos ultrapassou o lucro das empresas, seu crescimento econômico e a remuneração média de todos os trabalhadores. Entre 1980 e 2004, John Bogle, o fundador do Vanguard Group, estima que a remuneração total dos CEOS aumentou $8,5 \%$ ao ano, ao passo que o lucro empresarial cresceu 2,9\% ao ano e a renda per capita, 3,1\% [cf. Bogle, 2008; Ackman, 2002]. Em 2006, os CEOs ganharam quatrocentas vezes mais que o trabalhador médio - uma diferença vinte vezes maior que em 1965 [cf. Hunt, 2007]7.

Além de mudar a maneira de avaliar o capital, o capitalismo tecnoburocrático ou do conhecimento deu origem à definição de um novo tipo de "capital" - o capital humano. Os dois economistas neoclássicos que formularam essa teoria - Schultz (1961 e 1980) e Becker (1962 e [1975] 1993) - receberam merecidamente o Prêmio Nobel de Economia, porque em vez de usarem o método hipotético-dedutivo para construir castelos no ar, perceberam a existência de um novo fato de grande significado histórico. Eles reconheceram que o conhecimento tinha se tornado semelhante ao capital físico e que o investimento em educação pelas famílias é o modo pelo qual os indivíduos “acumulam” esse patrimônio e dele derivam ganhos ou rendimentos. Mais amplamente, as despesas (na verdade, investimentos)
7. Trecho extraído e traduzido do verbete "Executive compensation in the United States" da Wikipédia, disponível em en.wikipedia.org/wiki/Executive_compensation_in_the_United_States, consultado em 4/11/2014. 
realizadas pelo Estado na educação foram sempre - e mais ainda após a Segunda Revolução Industrial - o determinante principal do desenvolvimento econômico no longo prazo. Além de tornar as pessoas mais capazes de produzir bens e serviços com maior valor adicionado per capita, que justificam maiores salários, a educação de muitos indivíduos - a generalização da educação para toda a sociedade - acarreta externalidades positivas que abrem caminho para a inovação e o aumento da eficiência social, de modo que o capital humano total criado é maior do que a soma dos capitais acumulados por cada indivíduo.

O capitalismo tecnoburocrático tende a ser mais eficiente, mais capaz de promover o desenvolvimento econômico, por esse caráter de investimento de que se revestem as despesas em educação e também pela capacidade que os profissionais têm de administrar com eficiência as organizações públicas e privadas. Nesses dois pontos, portanto, há uma clara relação entre o capitalismo tecnoburocrático, que pensa as sociedades modernas por meio das classes sociais, e o desenvolvimentista, que as pensa em termos do desenvolvimento econômico.

\section{Dominação tecnoburocrática inevitável?}

Os argumentos baseados na concepção de uma "necessidade histórica" são perigosos. Frequentemente são fruto de um determinismo ingênuo, serviram para justificar ou dar forças ao desejo de mudança, em vez de explicar o desenrolar da história. Foi o caso da previsão da vitória inevitável do socialismo e também da tese neoliberal da convergência de todas as formas de capitalismo para o modelo anglo-saxão. É, portanto, equivocado prever a substituição da sociedade capitalista pela sociedade estatal ou tecnoburocrática. Na formação social mista que é o capitalismo tecnoburocrático, as relações entre capitalistas e profissionais são de constante cooperação e conflito, seja em termos individuais, seja em termos de classes sociais. Da mesma forma que a burguesia e a aristocracia competiram durante séculos por poder e privilégio, no século xx é a classe tecnoburocrática que empreende essa competição, tendo a burguesia como adversária e parceira ao mesmo tempo. Essa disputa, porém, dificilmente levará à dominação tecnoburocrática. A burguesia que ainda controla as empresas tem necessidade dos profissionais para administrar suas empresas, enquanto a burguesia rentista, formada de acionistas, depende dos altos tecnoburocratas que dirigem grandes organizações empresariais. Quanto à tecnoburocracia pública, toda a sociedade 
necessita da competência dos gestores públicos para o grande aparelho do Estado dos nossos dias. Além de detentores do conhecimento técnico e organizacional e responsáveis pela racionalidade instrumental ou eficiência, eles são também agentes da segurança; uma segurança que depende da capacidade regulatória das organizações e, principalmente, da instituição organizacional maior que eles administram - o Estado. Isso não impede, entretanto, que a classe capitalista reaja contra esse aumento de poder dos profissionais, como vimos acontecer nos anos neoliberais. Também não impede - o que é mais importante - outro tipo de resistência, que é a democrática. Esta, originada na massa de trabalhadores constituída por operários e empregados, luta por um Estado social mais amplo - que implica diminuição das desigualdades e uma maior participação no poder político - e pela democracia participativa.

Não se imagine, portanto, que a dominação tecnoburocrática seja inevitável. A definição do conhecimento técnico e organizacional como novo fator estratégico de produção aponta nessa direção, mas considerá-la necessária seria cair no determinismo economicista. A formação social na qual a classe profissional era ou se supunha todo-poderosa - as sociedades estatais que se pretendiam socialistas - revelou-se inviável. Isso aconteceu porque esse tipo de sociedade se mostrou menos eficiente do que a capitalista quando seu problema econômico deixou de ser a construção da infraestrutura e da indústria pesada para se tornar a coordenação de um número imenso de pequenas e médias empresas. Nessa tarefa, na qual não faz sentido o planejamento, o mercado é uma instituição de coordenação muito mais eficiente que o Estado. Outro motivo é o caráter autoritário do estatismo. Nas sociedades modernas, a demanda dos cidadãos pelos direitos civis, políticos e sociais é muito forte e resulta na garantia das liberdades civis, na democracia e no Estado social.

Mas não são apenas os estatistas que resistem à democracia; os liberais econômicos também sempre resistiram a ela. Afinal, aceitaram uma democracia liberal e estritamente representativa, ao passo que o tipo de democracia que avançou em todo o mundo, ainda que desequilibradamente, foi o da democracia social e, em menor grau, o da democracia participativa. No Estado moderno e democrático, a burocracia pública eleita e não eleita tem um enorme poder sobre o aparelho do Estado ou sua administração pública, mas, como também acontece com os capitalistas rentistas, seu poder é limitado pela democracia. Portanto, o poder tecnoburocrático continuará a ser contestado tanto pela burguesia rentista como pelos trabalhadores e pelas classes médias de empregados (o estrato inferior da classe profissional) em nome da democracia, um regime político que, impulsionado pelas classes 
populares, não deixa de avançar em quase todos os países na medida em que eles historicamente rejeitam o autoritarismo.

Em síntese, o capitalismo tecnoburocrático não é apenas definido pelas lógicas do capital e da organização; é definido também pela lógica da democracia. E esta, definitivamente, não é a lógica nem dos capitalistas, nem dos tecnoburocratas, mas dos trabalhadores ou dos pobres; é a lógica da participação democrática e da redução das desigualdades. Os capitalistas e seus ideólogos liberais querem reduzir a democracia à lógica do capital portanto, à democracia liberal na qual a participação popular é mínima -, ao passo que os tecnoburocratas sonham com uma organização econômica e política puramente racional. Mas creio ser possível afirmar que o entendimento da democracia pelas classes populares não é esse, e sim o de uma democracia social e participativa. Não é mais possível pensar a sociedade sem considerar a democracia e um lento, mas contínuo, processo de democratização, que leva o regime político da democracia liberal à democracia participativa e social.

Na virada do século XIX para o XX, aproximadamente ao mesmo tempo que a revolução organizacional dava origem à classe profissional, houve um segundo fato histórico novo: a transição, na maioria dos países hoje ricos, de regimes autoritário-liberais (que garantiam os direitos civis mas rejeitavam o sufrágio universal) para regimes democráticos em que as liberdades civis e o direito universal de eleger e ser eleito foram assegurados. Essa transição - uma verdadeira revolução democrática - teve consequências profundas sobre a forma de organizar e coordenar as sociedades modernas. A partir do momento em que cada nação transita do autoritarismo para a democracia, os trabalhadores associados a uma minoria de profissionais e capitalistas com espírito republicano buscam construir uma sociedade menos injusta ou mais igualitária do que a do capitalismo clássico ou liberal; buscam construir um Estado social e uma democracia participativa. Mas essa mudança não acontece do dia para a noite. A primeira forma de democracia é meramente liberal - é ainda uma democracia de elites. Entretanto, a partir da sua conquista, a melhoria da qualidade da democracia - a democratização - torna-se inevitável. Em consequência das lutas políticas, a democracia, sem deixar de ser representativa, tende a se tornar social (ao garantir, além dos direitos políticos, os sociais) e, mais tarde, participativa (ao incluir mecanismos de democracia consultiva sob a forma dos mais diversos conselhos) e parcialmente direta, na medida em que referendos e plebiscitos passam a se tornar frequentes. 
É através dessas três lógicas - lógica do capital, que é a do lucro e a da acumulação; lógica da organização, que é a do mérito e da eficiência; lógica da democracia, que é a da participação e da igualdade - e não apenas das duas primeiras que o Estado e as sociedades contemporâneas são socialmente construídos. Faço essa afirmação com base em minha crença no progresso, mas sei bem que os retrocessos políticos e sociais são sempre possíveis. O neoliberalismo inclui-se nessa categoria e, embora tenha sido profundamente abalado pela crise financeira global de 2008, não foi ainda definitivamente vencido.

\section{Referências Bibliográficas}

AcKman, Dan. (2002), "Pay madness at Enron". Forbes, 22 mar. Disponível em www. forbes.com/2002/03/22/0322enronpay.html, consultado em 4/11/2014.

BECKER, Gary S. (1962), "Investment in human capital: a theoretical analysis". Journal of Political Economy, n. 70.

. ([1975] 1993), Human capital. Berkeley/Chicago, University of Chicago Press.

BogLE, John C. (2008), "Reflections on ceo compensation”. Academy of Management Perspectives, 22 (2): 21-25. Disponível em amp.aom.org/content/22/2/21.full, consultado em 4/11/2014.

Drucker, Peter F. (1968), The age of discontinuity. Londres, Heinemann. . (1993), Post-capitalist society. Nova York, Harper Business.

Galbraith, John Kenneth. (1968), O novo Estado industrial. Rio de Janeiro, Civilização Brasileira.

. (2004), The economics of innocent fraud. Boston, Houghton Mifflin Company.

Gellner, Ernest. (1983), Nations \& nationalism. Ithaca, NY, Cornell University Press. GLYN, Andrew. (2007), Capitalism unleashed. Oxford, Oxford University Press.

Holmestron, B. \& Kaplan, S. (2003), "The state of us corporate governance: what is right and what is wrong". Texto para discussão NBER, n. 9613.

Hunt, Albert R. (2007), “Letter from Washington: as us rich-poor gap grows, so does public outcry”. Bloomberg News, 18 fev. Disponível em archive.today/39Ywd\#se lection-463.0-463.74, consultado em 4/11/2014.

Lash, Scott \& Urry, John. (1987), The end of organized capitalism. Cambridge, Polity Press.

MarX, Karl. ([1858] 1971), Grundrisse: elementos fundamentales para la crítica de economía política. Buenos Aires, Siglo XXI, 1971. . ([1867] 1968), O capital: livro I. Rio de Janeiro, Civilização Brasileira. 
Offe, Claus. ([1985] 1989), Capitalismo desorganizado. São Paulo, Brasiliense.

PIKeTty, Thomas. (2013), Le capital au XXième siècle. Paris, Seuil.

PrZeworski, Adam. (1985), Capitalism and social democracy. Cambridge, Cambridge University Press.

Schultz, Theodore W. (1961), "Investment in human capital". American Economic Review, 51 (1): 1-17.

(1980), Investing in people. Berkeley, University of California Press.

WARnER, William Lloyd. (1953), American life: dream and reality. Chicago, University of Chicago Press.

Weber, Max. ([1922] 1978), Economy and society. Berkeley, University of California Press.

ZeITLIN, Maurice. (1989), The large corporation and contemporary classes. New Brunswick, Rutgers University Press. 


\section{Resumo}

\section{Capital e organização no capitalismo tecnoburocrático}

Este artigo discute a formação social mista - capitalismo tecnoburocrático - que resultou da emergência da classe tecnoburocrática e da resiliência do capitalismo. Essa emergência ocorre com a Segunda Revolução Industrial e a consequente revolução organizacional, isto é, a mudança da unidade básica de produção da empresa familiar para as organizações empresariais. $\mathrm{O}$ trabalho concentra-se em dois aspectos desse processo histórico: a denominação de "organização" para a nova relação de produção e a mudança nas definições de capital pelo fato de que, no presente, nas sociedades tecnoburocrático-capitalistas, a burguesia e os profissionais compartilham poder e privilégios. $\mathrm{O}$ artigo termina com uma advertência: não há uma tendência para a dominação ou para as lógicas dos capitalistas (o capital) ou dos tecnoburocratas (a organização), porque há uma terceira lógica nas sociedades contemporâneas: a lógica das classes populares, a lógica da democracia.

Palavras-chave: Capitalismo tecnoburocrático; Capital; Organização.

\section{Abstract}

\section{Capital and organization in technobureaucratic capitalism}

This paper discusses the mixt social formation - technobureaucratic capitalism which resulted from the emergence of the technobureaucratic class and the resilience of capitalism. This emergence takes place with the Second Industrial Revolution and the consequent organizational revolution - the change of the basic unit of production from the family firm to the business organizations. The paper focus in two aspects of this historical process: the definition of the "organization" as the name of the new relation of production, and the change in the definitions of capital that goes together with the fact that, today, in technobureaucratic capitalist societies, capitalists and technobureaucrats share power and privilege. The paper ends with a caveat: there is no tendency to the domination either of the logic of capitalists (the capital), or of the technobureaucrats (the organization), because there is a third logic in contemporary societies: the logic of the popular classes - the logic of democracy.

Keywords: Technobureaucratic capitalism; Capital; Organization.
Texto enviado em 11/7/2014 e aprovado em 28/8/2014.

Luiz Carlos Bresser-Pereira é professor emérito da Fundação Getúlio Vargas e editor da Revista de Economia Política. E-mail: bresserpereira@gmail.com. 